\title{
Interventions that Facilitate Shared Decision-Making in Cancers with Active Surveillance as Treatment Option: a Systematic Review of Literature
}

\author{
G. E. Collée ${ }^{1}$ - B. J. van der Wilk ${ }^{2}$ (D) - J. J. B. van Lanschot ${ }^{2}$ J. J. Busschbach ${ }^{1} \cdot$ L. Timmermans ${ }^{3} \cdot$ S. M. Lagarde ${ }^{2}$. \\ L. W. Kranenburg ${ }^{1}$
}

Published online: 28 July 2020

(C) The Author(s) 2020

\begin{abstract}
Purpose of review Medical decisions concerning active surveillance are complex, especially when evidence on superiority of one of the treatments is lacking. Decision aids have been developed to facilitate shared decision-making on whether to pursue an active surveillance strategy. However, it is unclear how these decision aids are designed and which outcomes are considered relevant. The purpose of this study is to systematically review all decision aids in the field of oncological active surveillance strategies and outcomes used by authors to assess their efficacy.

Recent findings A search was performed in Embase, Medline, Web of Science, Cochrane, PsycINFO Ovid and Google Scholar until June 2019. Eligible studies concerned interventions aiming to facilitate shared decision-making for patients confronted with several treatment alternatives, with active surveillance being one of the treatment alternatives. Twenty-three eligible articles were included. Twenty-one articles included patients with prostate cancer, one with thyroid cancer and one with ovarian cancer. Interventions mostly consisted of an interactive web-based decision aid format. After categorization of outcomes, seven main groups were identified: knowledge, involvement in decision-making, decisional conflict, treatment preference, decision regret, anxiety and health-related outcomes.

Summary Although active surveillance has been implemented for several malignancies, interventions that facilitate shared decision-making between active surveillance and other equally effective treatment alternatives are scarce. Future research should focus on developing interventions for malignancies like rectal cancer and oesophageal cancer as well. The efficacy of interventions is mostly assessed using short-term outcomes.
\end{abstract}

Keywords Active surveillance $\cdot$ Decision aid $\cdot$ Shared decision-making

G. E. Collée and B. J. van der Wilk contributed equally to this work.

This article is part of the Topical Collection on Palliative Medicine

Electronic supplementary material The online version of this article (https://doi.org/10.1007/s11912-020-00962-3) contains supplementary material, which is available to authorized users.

B. J. van der Wilk

b.vanderwilk@erasmusmc.nl

1 Department of Psychiatry, Section Medical Psychology and Psychotherapy, Erasmus MC - University Medical Centre, Rotterdam, Netherlands

2 Department of Surgery, Erasmus MC - University Medical Centre, Dr. Molewaterplein 40 P.O. Box 2040, Suite Na-2119, 3015 GD Rotterdam, Netherlands

3 Department of Primary and Community Care, Radboud University Medical Centre, Nijmegen, Netherlands

\section{Introduction}

Treatment modalities for cancer include a combination of radiotherapy, chemotherapy and surgery. In addition, active surveillance has been introduced as an alternative treatment option in prostate, colorectal, thyroid and head and neck cancer $[1-5,6 \bullet, 7]$. In other malignancies such as oesophageal cancer, active surveillance is under investigation as a viable treatment option $[8 \bullet, 9]$. Active surveillance involves frequently performed response evaluations after neoadjuvant therapy using diagnostics (e.g. imaging scans and endoscopic biopsies) to detect remnants of residual disease. Additional treatment is only indicated in those patients with residual disease or progression of disease. Active surveillance strategies have potential advantages, such as the possibility to avoid or delay the need for invasive treatments associated with morbidity and 
even mortality. However, pitfalls in an active surveillance strategy include the development of an unresectable recurrence, possibly resulting in deterioration of overall survival. Furthermore, distant dissemination rates could theoretically increase due to longer presence of residual tumour in the primary organ, possibly resulting in shedding of tumour cells and development of metastases [10]. In addition, several studies reported that active surveillance induces a certain degree of uncertainty and anxiety for patients, because they might feel like they are living with 'untreated' cancer [11-13•]. Finally, the repeated diagnostic measures may also cause a physical burden (e.g. endoscopy) and periodical peaks of anxiety, with possible negative effects on quality of life [14].

Medical decisions concerning active surveillance are often complex, especially because there are multiple treatment options without a clear indication for the best oncological outcome at a group level, let alone at an individual level. The choice of treatment therefore depends on the preferences and values of individual patients as well as their treating physicians. It is preferable that physicians and patients participate in shared decision-making to ensure that the decision made is consistent with the patient's preferences [15]. Shared decision-making involves informing the patient that a decision is to be made, explaining the potential advantages and disadvantages of each relevant option, discussion of patient's preferences and finally making the decision together [16]. In order to help patients and physicians making informed decisions together, various interventions have been developed. However, it is unclear how to measure whether these interventions indeed facilitate shared decision-making [17, 18].

In this systematic review, we aim to summarize the design of an intervention and the outcomes that are considered relevant to measure the effectiveness of an intervention used to facilitate shared decision-making in cancer patients for whom active surveillance is a treatment alternative.

\section{Methods}

\section{Protocol and Registration}

The protocol for this study was specified in advance and registered on Prospero (CRD42020139240). The study was performed according to the PRISMA guidelines for systematic reviews [19].

\section{Eligibility Criteria}

Studies were considered eligible if (1) patients were included with malignant disease; (2) on the patients, a choice was imposed between several treatment options, with active surveillance being one of the alternatives; (3) an intervention was used to facilitate shared decision-making; and (4) the outcomes used to measure the effectiveness of the intervention were reported. Interventions were defined as all methods or approaches designed to facilitate involvement in the decisionmaking process for medical treatment. No restrictions were placed on outcome measures. There was no restriction on publication date. Letters to the editor, editorials, conference abstracts, systematic reviews, narrative reviews and studies written in other languages than English were excluded from further analysis. Also, studies including only patients with palliative options were excluded from further analysis.

\section{Information Sources and Search}

The search strategy was developed in collaboration with an experienced research librarian with an expertise in systematic review searching. The search was applied to Embase and adapted to Medline Ovid, Web of Science, Cochrane Central, PsychINFO Ovid and Google Scholar until June 13, 2019. In addition to these electronic database searches, included papers were checked for relevant references. Search terms included 'watchful waiting' or 'active surveillance' combined with 'shared decision' or 'decision making' or 'patient preference' or 'decision aid/tool' and 'cancer (treatment)'. The full search strategy is reported in Supplementary Table 1.

Endnote X9 (Thomas Reuters, New York, NY) was used for the reference management of the literature search results. After deduplication, two authors ( $\mathrm{GC}$ and $\mathrm{BvdW}$ ) independently screened titles and abstracts of the articles from the search results and selected studies based on the predefined inclusion and exclusion criteria. Inconsistencies were resolved by discussion between the two authors. If no consensus was reached, a third author (LK) resolved any disagreement. The full-text articles were then screened, and motivations for exclusion were recorded. Finally, references of eligible studies were screened for relevance, and references of previously published reviews on this topic were screened for cross-referencing.

\section{Data Extraction}

A data extraction form was developed in order to identify key information and recurring themes within studies. The data extraction form was pilot-tested and refined accordingly. One author (GC) extracted data from included studies, and a second author (BvdW) checked the extracted data. Again, disagreements were resolved by discussion, and if no agreement was reached, a third author made a final decision (LK). Information was extracted from the included studies on (1) characteristics of included participants and studies, including number of patients and type of malignancy as well as the design of the study; (2) type of intervention used; (3) outcomes as measured by authors; (4) instruments used for the assessment of the effectiveness of intervention; and (5) reported results for every outcome. In the present study, the Critical 
Appraisal Skills Programme (CASP) was used for the assessment of quality of included qualitative studies [20]. For included randomized controlled trials, the risk of bias was assessed using the Cochrane Collaboration's tool for RCTs, and the ROBINS-I tool was used for assessing risk of bias in non-randomized studies [21, 22].

\section{Results}

\section{Study Selection}

A total of 23 articles, describing 22 unique interventions, were included in this systematic review. From six databases, 4856 articles were identified, and 16 articles were identified through cross-referencing. After adjusting for duplicates, 2912 articles were eligible for title and abstract screening. Of these, 2884 were excluded through title and abstract screening, not meeting the inclusion criteria. After 28 full-text analyses, five additional studies were excluded, ultimately leaving 23 relevant articles. A detailed flowchart for exclusion at each stage and reasons for exclusion after full-text analyses is reported in Fig. 1. Two articles were based on the same trial, but since they measured different outcomes, both studies were included $[23,24]$. The results of the risk of bias assessments of all studies are summarized in supplementary Fig. 1a-c. Results and outcomes of the included articles are summarized in Tables 1 and 2 .

\section{Study and Patient Characteristics}

Of 23 articles included in this study, twelve were randomized controlled trials, which all except one included over 100 patients. Non-randomized trials were mainly cohort studies of which four studies included over 100 patients. Twenty-one articles included patients with prostate cancer, one article included only patients with thyroid cancer and one only patients with ovarian cancer.

\section{Type of Intervention}

In the majority of studies, an interactive web-based decision aid (DA) format was used [23, 24, 28-30, 38, 42, 43, 45]. These DAs included written information, videos and/ or exercises offering patients the opportunity to consider
Fig. 1 Flow diagram of literature search and study selection

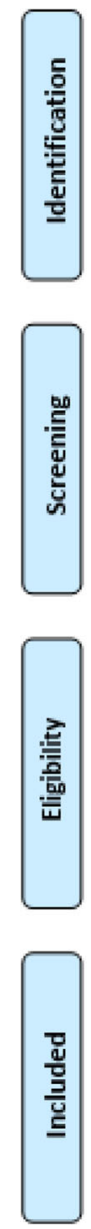




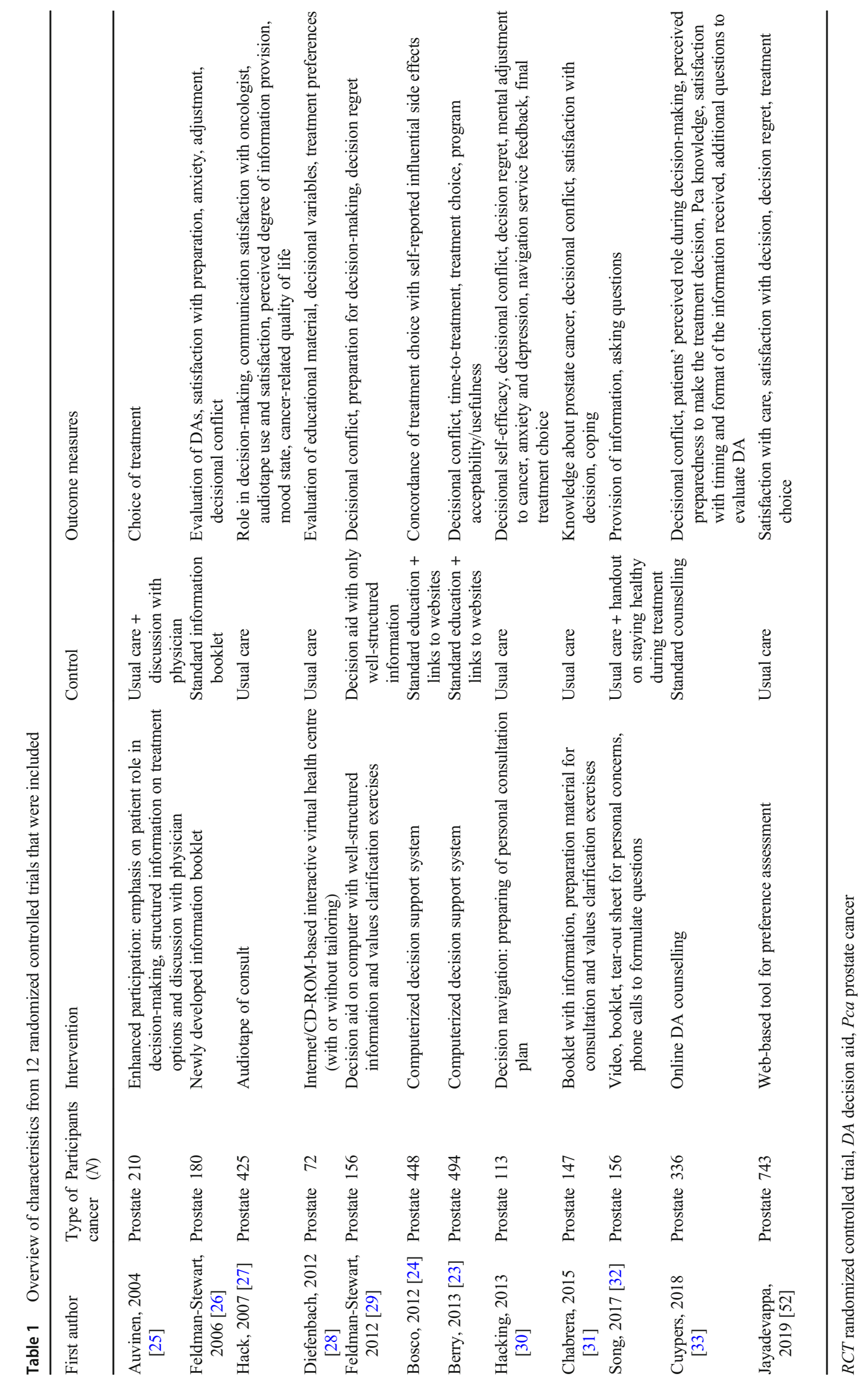


Table 2 Overview of characteristics from 11 non-randomized controlled trials that were included

\begin{tabular}{|c|c|c|c|c|}
\hline Study & $\begin{array}{l}\text { Type of } \\
\text { cancer }\end{array}$ & Participants $(N)$ & Intervention & Outcome measures \\
\hline Onel, 1998 [34] & Prostate & 111 & Video presentation & $\begin{array}{l}\text { Knowledge of prostate cancer, subjective participation in } \\
\text { treatment decision, final treatment decision, satisfaction with } \\
\text { choice, would choose again }\end{array}$ \\
\hline Kim, $2001[35]$ & Prostate & 30 & $\begin{array}{l}\text { Interactive CD-ROM } \\
\text { decision aid }\end{array}$ & $\begin{array}{l}\text { Prostate cancer knowledge, satisfaction with DA, treatment } \\
\text { preference, likelihood of following treatment preference, } \\
\text { relationship between Pca knowledge and health literacy }\end{array}$ \\
\hline McGregor, 2003 [36] & Prostate & $\begin{array}{l}10 \text { healthy men, } 12 \\
\text { patients }\end{array}$ & Video presentation & $\begin{array}{l}\text { Insight and knowledge after consultation, communicative } \\
\text { effectiveness of video DA, effect of diagnosis on memory and } \\
\text { perception, mastery over situation }\end{array}$ \\
\hline $\begin{array}{l}\text { Feldman-Stewart, } \\
2004[37]\end{array}$ & Prostate & 60 & $\begin{array}{l}\text { Decision aid (one-on-one) } \\
\text { interview }\end{array}$ & $\begin{array}{l}\text { Attributes important to the decision, cognitive challenges as } \\
\text { determined by patients, changes in important attributes over } \\
\text { decision process, changes in treatment ratings, cognitive } \\
\text { processes associated with stability of preferred treatment } \\
\text { options, cognitive processes associated with regret }\end{array}$ \\
\hline $\begin{array}{l}\text { Holmes-Rovner, } \\
2005 \text { [38] }\end{array}$ & Prostate & 60 & $\begin{array}{l}\text { Booklet DA, internet DA } \\
\text { and audiotape DA }\end{array}$ & $\begin{array}{l}\text { Different media outcomes, clarity and usefulness of DA, } \\
\text { knowledge of pathology results, knowledge of treatment } \\
\text { options, discussion of treatment options with physician, active } \\
\text { role in treatment decision }\end{array}$ \\
\hline Isebaert, 2008 [39] & Prostate & 50 & $\begin{array}{l}\text { Decision aid booklet (based } \\
\text { on Holmes-Rovner) }\end{array}$ & $\begin{array}{l}\text { Patients' general evaluation of the decision aid, final treatment } \\
\text { choice, impact of decision aid on treatment choice and } \\
\text { consultation according to patients, impact of decision aid on } \\
\text { treatment choice and consultation according to doctor }\end{array}$ \\
\hline Anderson, 2011 [40] & Ovarian & 20 & Decision aid booklet & $\begin{array}{l}\text { Information and involvement preferences, decision aid feedback, } \\
\text { understanding of information contained in DA, difficulties and } \\
\text { satisfaction with the decision-making process, anxiety levels }\end{array}$ \\
\hline Formica, 2017 [41] & Prostate & 452 & Video presentation & Knowledge of the rationale for active surveillance \\
\hline Lamers, 2017 [42] & Prostate & 181 & $\begin{array}{l}\text { Web-based DA with } \\
\text { information + values } \\
\text { clarification exercises }\end{array}$ & $\begin{array}{l}\text { Concordance of treatment preference before and after DA use, } \\
\text { concordance of treatment preference after DA and final } \\
\text { choice, concordance initial treatment preference patient and } \\
\text { urologist, concordance urologist preference with final decision }\end{array}$ \\
\hline Myers, 2018 [43] & Prostate & 30 & $\begin{array}{l}\text { Nurse-mediated online } \\
\text { software application }\end{array}$ & $\begin{array}{l}\text { Knowledge about Pca and treatment, patient perceptions } \\
\text { regarding Pca and treatment, decisional conflict, treatment } \\
\text { preference, treatment status }\end{array}$ \\
\hline Brito, 2018 [44] & Thyroid & 278 & Conversation aid & Final treatment choice \\
\hline
\end{tabular}

$D A$ decision aid, $P c a$ prostate cancer

what they deemed important regarding the treatment choice of their disease. Six studies used an informational booklet, containing information on the disease, different treatment options and the possible side effects of each treatment option [26, 31, 32, 38-40]. In four studies, a video presentation was the main tool of the DA [32, 34, $36,41]$. In one study, participants received an audiotape DA [38]. Two studies assessed the effect of providing an audiotape of the consultation of the patients with their physician [27, 30]. In five studies, the DA primarily involved an additional consultation with an expert $[25,30$, $37,43,44]$. Three studies explicitly mentioned the added value of clarification exercises to the DA [29, 31, 42]. Please note that some studies did not use only one type of intervention, but a combination of, for example, an information booklet and a web-based DA.

\section{Effectiveness of Decision Aid}

An overview of the different outcomes measured by the authors is offered in Tables 1 and 2. A large heterogeneity exists in these outcomes. In order to acquire more insights into the outcome measures, seven groups were constructed by categorizing the outcomes according to most occurring related outcome measures. These groups are knowledge, involvement in decision-making, decisional conflict, treatment preference/ choice, decision regret/satisfaction with decision, anxiety/coping/mood and health-related outcomes. Knowledge was measured in 7 studies, involvement in decision-making in 10 studies, decisional conflict in 9 studies, treatment preference/ choice in 13 studies, decision regret/satisfaction with decision in 6 studies, anxiety/coping/mood in 5 studies and healthrelated outcomes in 1 study. 
Four questionnaires were used frequently by different authors: the Preparation for Decision Making Scale, the Decisional Conflict Scale, the Decision Regret Scale and the Satisfaction with Decision Scale. Knowledge and evaluation of DA were often measured with questionnaires developed by the authors. The results of each individual study assessing the effectiveness of the intervention used are summarized in Table 3. Only one study measured outcomes specific to active surveillance, and this outcome was 'knowledge of the rationale for active surveillance' [41].

Out of the 23 studies, eleven added the patients' evaluation of their DA as an outcome measure [23, 26-28, 30, 33, 35, 36, 38-40]. In these studies, patients were asked for their feedback concerning acceptability, feasibility, clarity, usefulness, satisfaction with timing and format of the information and satisfaction with DA in general or communicative effectiveness.

\section{Discussion}

This systematic review presents an overview of interventions aimed at facilitating shared decision-making in cancer patients who are confronted with a treatment choice in which active surveillance is a treatment alternative and the outcomes are considered relevant in this respect. Surprisingly, even though active surveillance is an established treatment alternative also for patients with rectal cancer head and neck cancer and is under investigation for oesophageal cancer, current interventions are mostly limited to patients with prostate cancer. The present study is the first systematic review that provides an overview of outcomes used to test the effectiveness of interventions aimed at facilitating shared decision-making in cancer when active surveillance is a treatment alternative. This resulted in an insight in the spectrum of interventions used, for what purpose and which outcomes have been measured.

Of the 23 included studies, 21 have developed decision aids for patients with prostate cancer. This is remarkable given that active surveillance has also been performed in patients with rectal cancer and head and neck cancer for over 15 years. Furthermore, in several malignancies, an active surveillance strategy has been topic of debate (e.g. oesophageal cancer). A recent systematic review assessed all studies that used decision aids for patients with colorectal cancer [46]. The authors of this study screened 3773 articles and eventually included three articles [47-49]. Of these three articles, two articles used the decision aid to support the decision between chemotherapy or no chemotherapy treatment. One article used the aid to choose between two surgical techniques. No decision aids were developed to support the decision including active surveillance, as is the focus of this systematic review.

The present study reported on 22 unique interventions. It seems that there is no consensus on which type of intervention is most effective. Booklets, videos and web-based DAs are the most commonly used interventions, and more recent studies sometimes included a consultation with a professional to talk about the preferences of the patient. Most interventions rely on the patients' own motivation to use the decision aid and to improve their understanding of the (dis)advantages of each treatment. As such, patients are expected to return to their physician with a better understanding of their disease after having used the specific DA. Most interventions also encourage the patient to consider their values and preferences. However, it remains unclear to what extent these values and preferences are taken into account in the consultation and final decision-making with the physician.

Finally, there is a large heterogeneity in the outcomes used by authors to assess the effectiveness of the tested interventions. After categorization of the outcomes, treatment choice or preference was most reported to test efficacy of interventions. The reason for this remains unclear, because DAs should not aim to increase the choice for a specific treatment but rather to facilitate shared decision-making by helping patients and their healthcare professionals make a treatment choice best fitted to their unique circumstances [50]. Whether or not the interventions succeeded in this respect is most probably not measured by assessing the treatment choice of the patient. We propose that self-reported involvement in decision-making could be a representative short-term outcome and decisional conflict could be a representative long-term outcome for the effectiveness of DAs. Indeed, self-reported involvement in decision-making was used as outcome in a large number of the articles. Decisional conflict, however, was used as outcome only in a minority of studies. This could be due to the fact that a longer follow-up is needed for this outcome. Even though all studies included in this review had active surveillance as a treatment option, only one study used an outcome measure specific to active surveillance, i.e. knowledge of the rationale for active surveillance [41]. There are usually no outcome measures specific to the other treatment options either; however, active surveillance seems different from the other treatment options. For active surveillance to be successful, it is very important that patients who choose active surveillance understand what it entails for both acceptance and adherence to the active surveillance strategy, as reported in a previous study [51].

The present study is associated with limitations. Firstly, because of the limited variety in malignancies discussed, mostly DAs for prostate cancer were analysed. Consequently, we assessed the outcomes for a selected group of patients, and as such, these results might not be one to one extrapolated to the general population. However, we included only malignancies that also involved active surveillance as treatment alternative, enhancing the generalizability among the malignancies with active surveillance as treatment option. Secondly, due to the large heterogeneity in outcomes used by the authors to assess the 


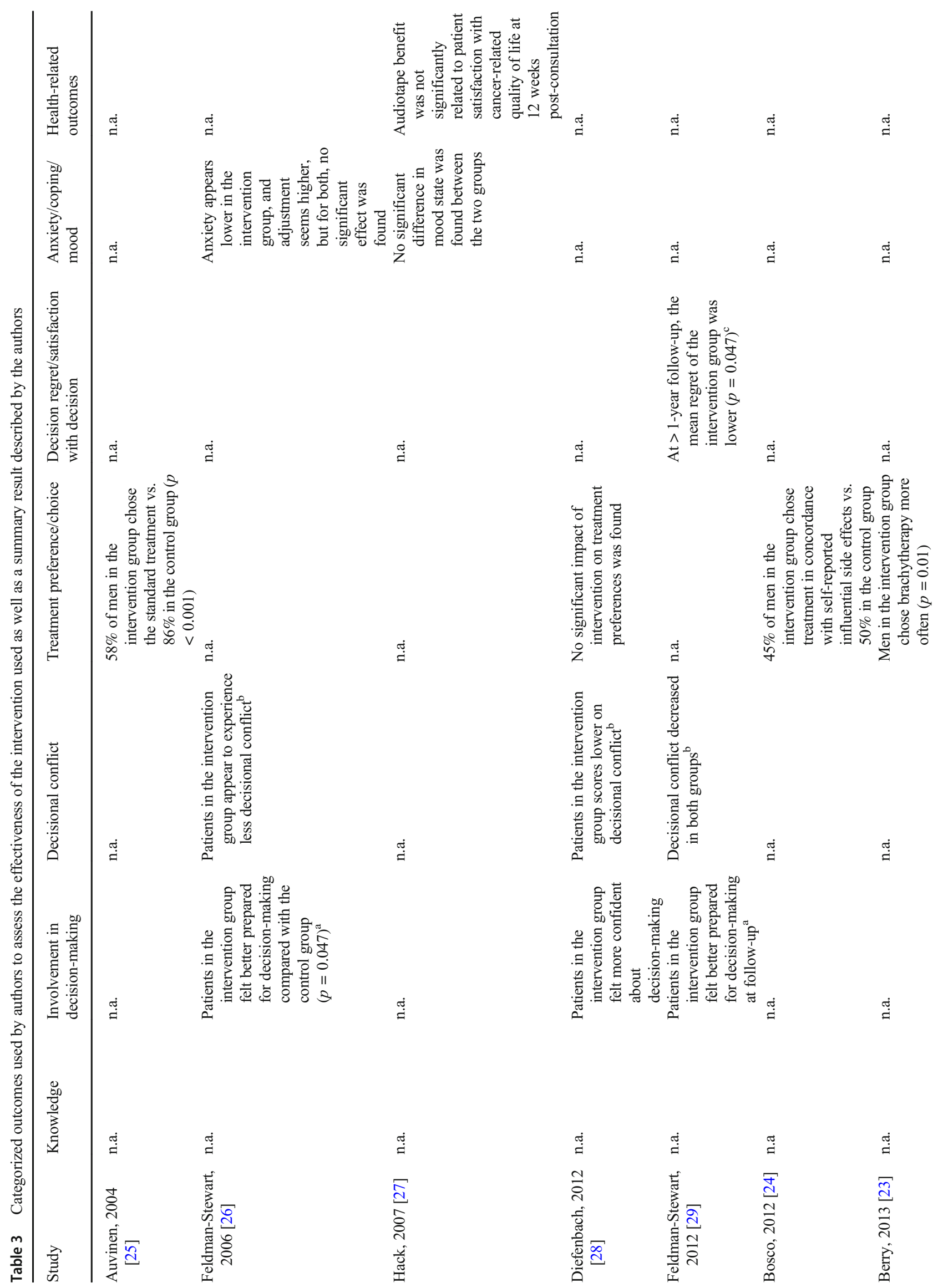




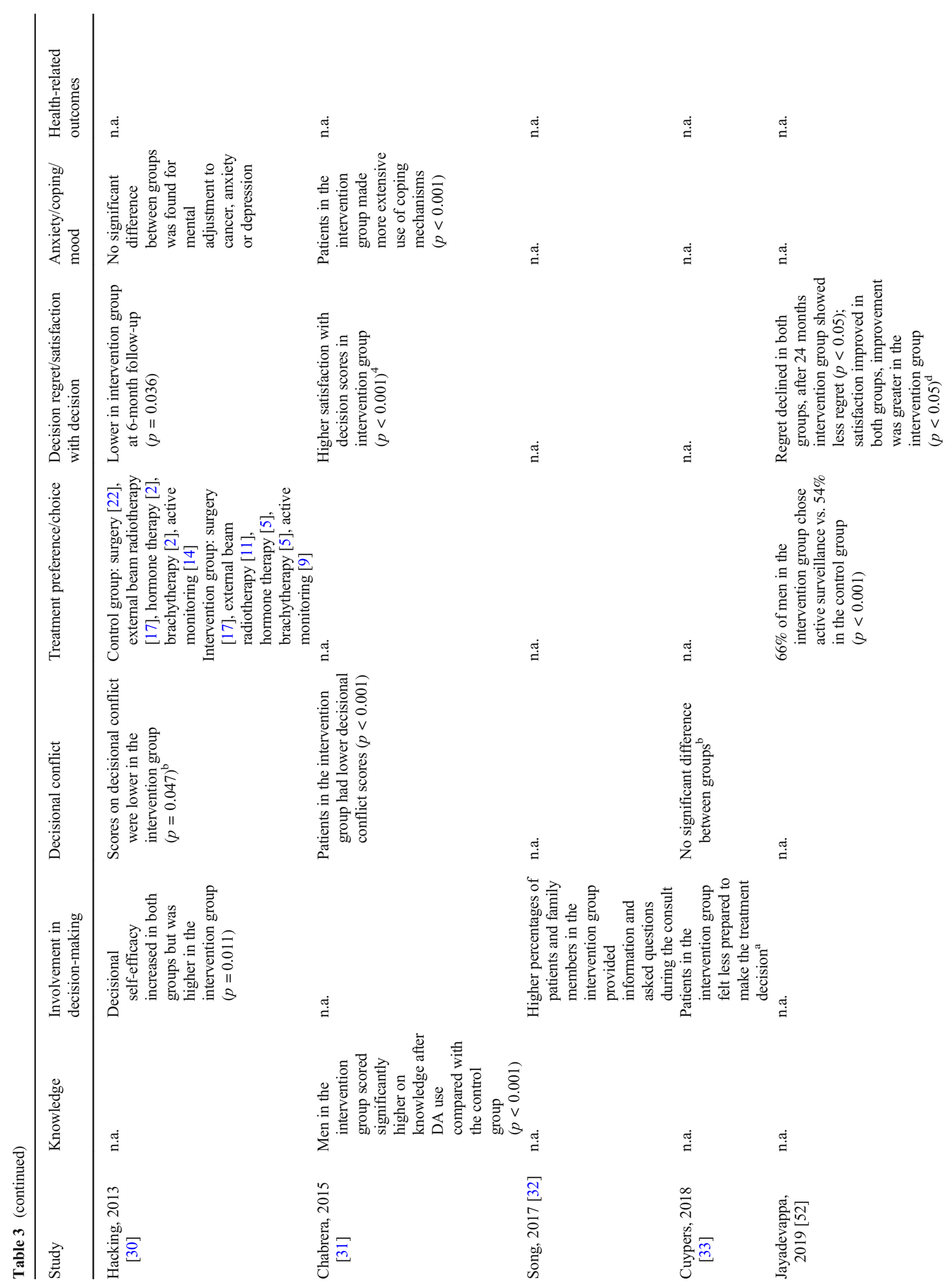




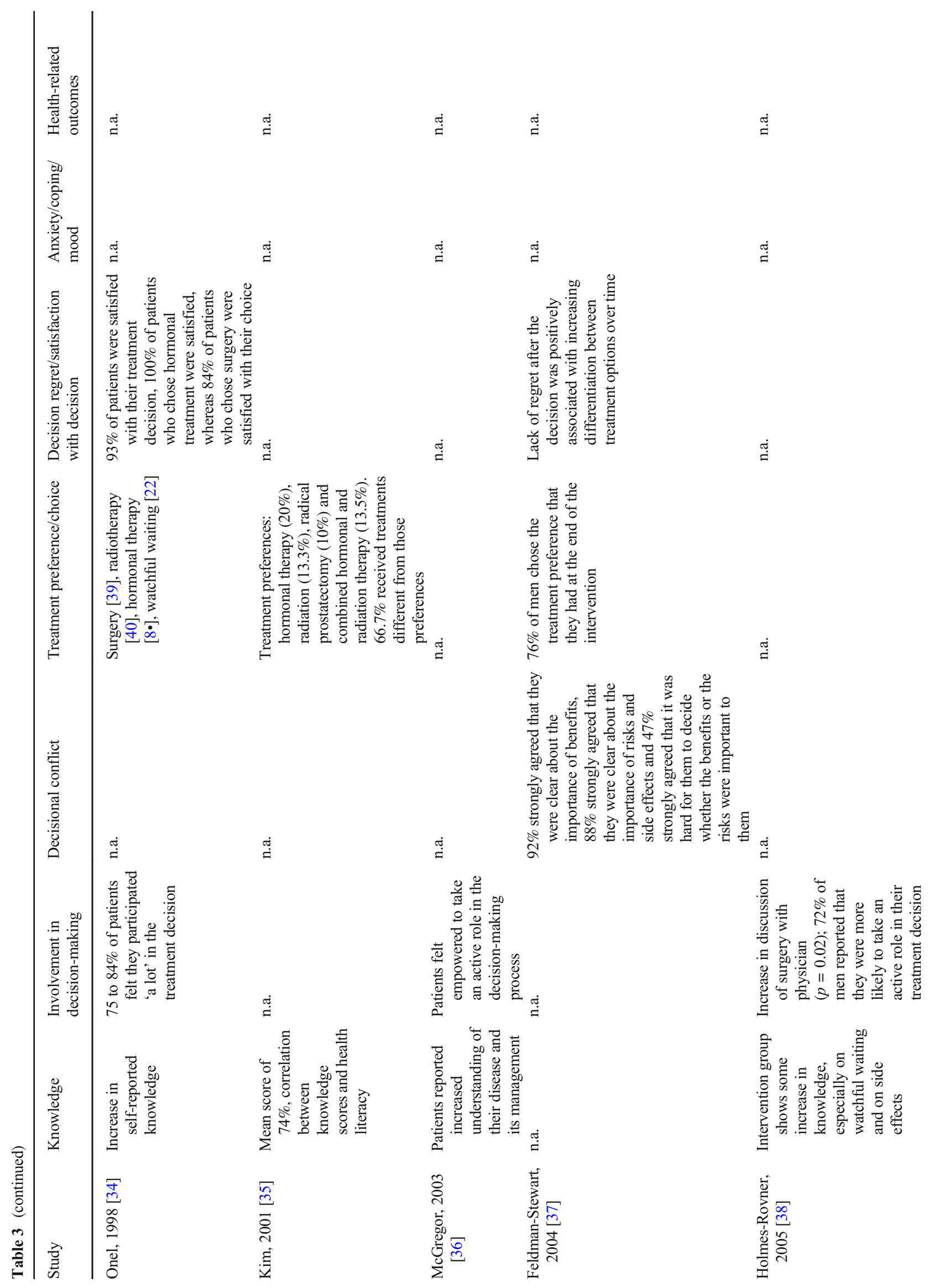




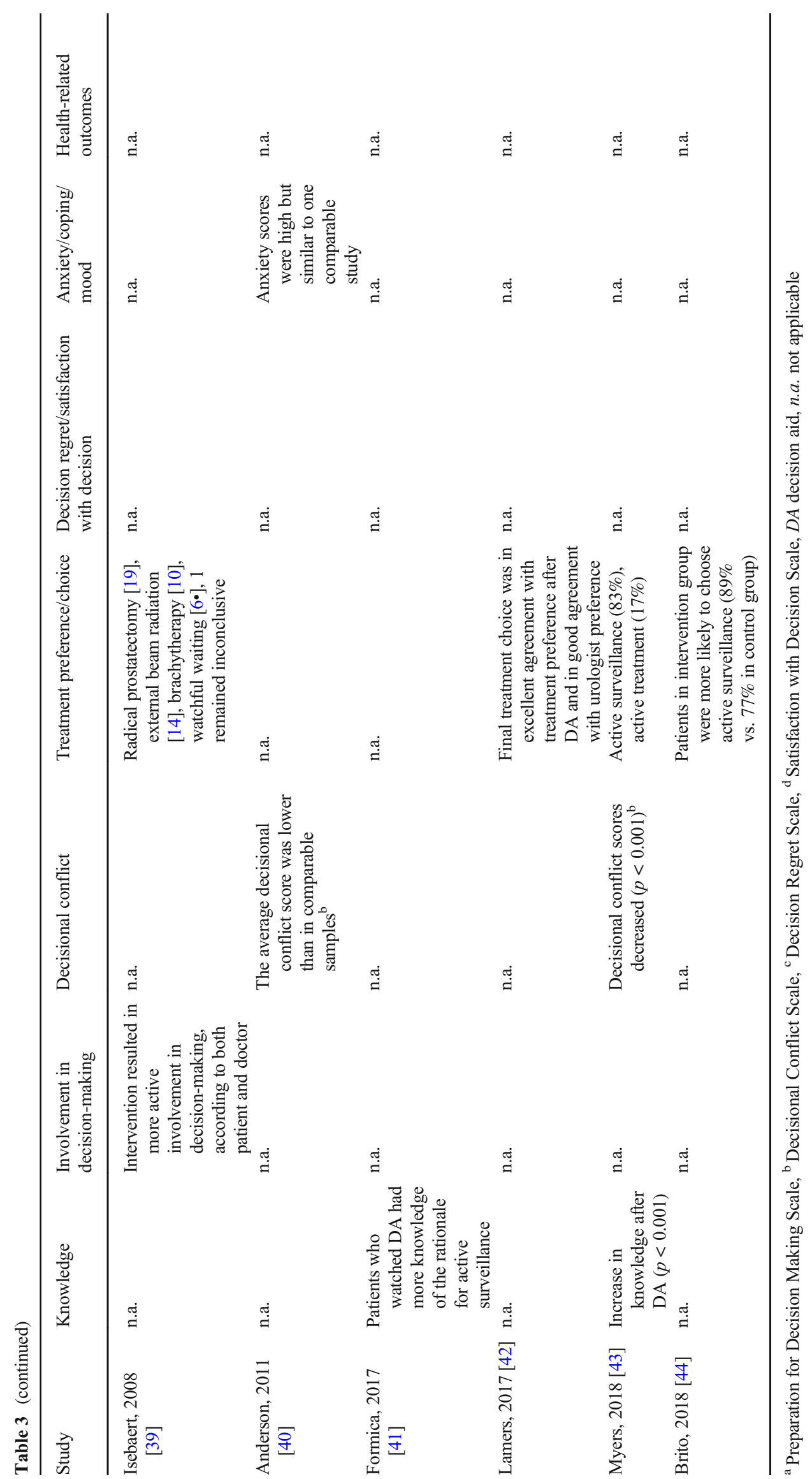


effectiveness of the intervention, a categorization of these outcomes was necessary for overview. Inevitably, in this way, interpretation of the results could not be avoided. Lastly, since both patients and physicians are involved in shared decision-making, it would be interesting to gain more insights in the evaluation of the developed interventions from a physician perspective. The current search strategy was not designed to answer this question.

\section{Conclusion}

In conclusion, interventions facilitating the choice between several treatment options with active surveillance as one of the alternatives have been developed mostly for prostate cancer, thus far. The outcomes used to assess the effectiveness of the interventions are highly heterogenic, and it remains unclear how interventions are exactly supposed to facilitate shared decision-making. Future research should focus on developing interventions for malignancies other than prostate cancer, like rectal cancer, head and neck cancer and oesophageal cancer. Furthermore, interventions that facilitate shared decision-making might benefit from more long-term followup research, measuring outcomes like decision regret. With active surveillance, patients have to return to the hospital regularly for a few years, and it would be interesting to see how the intervention affects patients after a year or more, especially regarding patient-reported outcomes like anxiety and decision regret.

Acknowledgements We would like to thank Mr. Wichor M. Bramer (Medical Library from Erasmus MC - University Medical Centre) for his assistance with setting up the systematic search.

\section{Compliance with Ethical Standards}

Conflict of Interest Berend Jan van der Wilk, Gerlise E. Collee, J. Jan B. van Lanschot, Jan J. Busschbach, Liesbeth Timmermans and Sjoerd M. Lagarde declare no conflict of interest. Leonieke W. Kranenburg is supported by a grant from the MLDS.

Human and Animal Rights and Informed Consent This article does not contain any studies with human or animal subjects performed by any of the authors.

Open Access This article is licensed under a Creative Commons Attribution 4.0 International License, which permits use, sharing, adaptation, distribution and reproduction in any medium or format, as long as you give appropriate credit to the original author(s) and the source, provide a link to the Creative Commons licence, and indicate if changes were made. The images or other third party material in this article are included in the article's Creative Commons licence, unless indicated otherwise in a credit line to the material. If material is not included in the article's Creative Commons licence and your intended use is not permitted by statutory regulation or exceeds the permitted use, you will need to obtain permission directly from the copyright holder. To view a copy of this licence, visit http://creativecommons.org/licenses/by/4.0/.

\section{References}

Papers of particular interest, published recently, have been highlighted as:

- Of importance

1. Choo R, Klotz L, Danjoux C, Morton GC, DeBoer G, Szumacher E, et al. Feasibility study: watchful waiting for localized low to intermediate grade prostate carcinoma with selective delayed intervention based on prostate specific antigen, histological and/or clinical progression. J Urol. 2002;167(4):1664-9.

2. Habr-Gama A, Perez RO, Nadalin W, Sabbaga J, Ribeiro U Jr, Silva e Sousa AH Jr, et al. Operative versus nonoperative treatment for stage 0 distal rectal cancer following chemoradiation therapy: long-term results. Ann Surg. 2004;240(4):711-7; discussion 7-8. https://doi.org/10.1097/01.sla.0000141194.27992.32.

3. Klotz L, Zhang L, Lam A, Nam R, Mamedov A, Loblaw A. Clinical results of long-term follow-up of a large, active surveillance cohort with localized prostate cancer. J Clin Oncol. 2010;28(1):126-31. https://doi.org/10.1200/JCO.2009.24.2180.

4. Maas M, Beets-Tan RG, Lambregts DM, Lammering G, Nelemans PJ, Engelen SM, et al. Wait-and-see policy for clinical complete responders after chemoradiation for rectal cancer. J Clin Oncol. 2011;29(35):4633-40. https://doi.org/10.1200/JCO.2011.37.7176.

5. Socha J, Kepka L, Michalski W, Paciorek K, Bujko K. The risk of distant metastases in rectal cancer managed by a watch-and-wait strategy - a systematic review and meta-analysis. Radiother Oncol. 2019;144:1-6. https://doi.org/10.1016/j.radonc.2019.10.009.

6. van der Valk, MJM, Hilling DE, Bastiaannet E, Meershoek-Klein Kranenbarg E, Beets GL, Figueiredo NL et al. Long-term outcomes of clinical complete responders after neoadjuvant treatment for rectal cancer in the International Watch \& Wait Database (IWWD): an international multicentre registry study. Lancet. 2018;391(10139): 2537-2545. https://doi.org/10.1016/S0140-6736(18)31078-X. This registry study aimed to describe an active surveillance strategy for patients with rectal cancer. After inclusion of $\mathbf{8 8 0}$ patients with a clinically complete response who underwent such a strategy, reasonable survival and metastases rates were found. This study confirms the feasibility of an active surveillance strategy in rectal cancer.

7. Vokes EE, Kies MS, Haraf DJ, Stenson K, List M, Humerickhouse $\mathrm{R}$, et al. Concomitant chemoradiotherapy as primary therapy for locoregionally advanced head and neck cancer. J Clin Oncol. 2000;18(8):1652-61. https://doi.org/10.1200/JCO.2000.18.8.1652.

8. van der Wilk, BJ, Noordman BJ, Neijenhuis LKA, Nieboer D, Nieuwenhuijzen GAP, Sosef MN et al. Active surveillance versus immediate surgery in clinically complete responders after neoadjuvant chemoradiotherapy for esophageal cancer: a multicenter propensity matched study. Ann Surg. 2019. https://doi.org/10.1097/ SLA. 0000000000003636 . This retrospective cohort study aimed to compare survival of patients with a clinically complete response undergoing either active surveillance or immediate surgery after neoadjuvant chemoradiotherapy. Both distant metastases rate and overall survival were comparable between both groups. Although results of randomized controlled trials need to be awaited, the results suggest that also in esophageal cancer an active surveillance strategy could be feasible.

9. Noordman BJ, Wijnhoven BPL, Lagarde SM, Boonstra JJ, Coene P, Dekker JWT, et al. Neoadjuvant chemoradiotherapy plus surgery versus active surveillance for oesophageal cancer: a stepped-wedge cluster randomised trial. BMC Cancer. 2018;18(1):142. https://doi. org/10.1186/s12885-018-4034-1. 
10. Fidler IJ. The pathogenesis of cancer metastasis: the 'seed and soil' hypothesis revisited. Nat Rev Cancer. 2003;3(6):453-8. https://doi. org/10.1038/nrc1098nrc1098.

11. Marzouk K, Assel M, Ehdaie B, Vickers A. Long-term cancer specific anxiety in men undergoing active surveillance of prostate cancer: findings from a large prospective cohort. J Urol. 2018;200(6):1250-5. https://doi.org/10.1016/j.juro.2018.06.013.

12. Anderson J, Burney S, Brooker JE, Ricciardelli LA, Fletcher JM, Satasivam $P$, et al. Anxiety in the management of localised prostate cancer by active surveillance. BJU Int. 2014;114(Suppl 1):55-61. https://doi.org/10.1111/bju.12765.

13. van den Bergh RC, Essink-Bot ML, Roobol MJ, Wolters T, Schroder FH, Bangma $\mathrm{CH}$ et al. Anxiety and distress during active surveillance for early prostate cancer. Cancer. 2009;115(17):386878. https://doi.org/10.1002/cncr.24446. Patients with early prostate cancer who underwent active surveillance received questionnaires concerning ddecisional conflict, depression and anxiety. This study emphazises the need to optimize patient selection who need supportive measures when an active surveillance strategy is implemented.

14. Watts S, Leydon G, Eyles C, Moore CM, Richardson A, Birch B, et al. A quantitative analysis of the prevalence of clinical depression and anxiety in patients with prostate cancer undergoing active surveillance. BMJ Open. 2015;5(5):e006674.

15. Barry MJ, Edgman-Levitan S. Shared decision making-pinnacle of patient-centered care. N Engl J Med. 2012;366(9):780-1. https:// doi.org/10.1056/NEJMp1109283.

16. Stiggelbout AM, Pieterse AH, De Haes JC. Shared decision making: concepts, evidence, and practice. Patient Educ Couns. 2015;98(10):1172-9.

17. Kennedy AD. On what basis should the effectiveness of decision aids be judged? Health Expect. 2003;6(3):255-68

18. Sepucha KR, Breslin M, Graffeo C, Carpenter CR, Hess EP. State of the science: tools and measurement for shared decision making. Acad Emerg Med. 2016;23(12):1325-31.

19. Moher D, Liberati A, Tetzlaff J, Altman DG, Group P. Preferred reporting items for systematic reviews and meta-analyses: the PRISMA statement. BMJ. 2009;339:b2535. https://doi.org/10. 1136/bmj.b2535.

20. Hannes K. Chapter 4: critical appraisal of qualitative research. In: Noyes J, Booth A, Hannes K, Harden A, Harris J, Lewin S, Lockwood C (editors), Supplementary guidance for inclusion of qualitative research in Cochrane systematic reviews of interventions. Version 1 (updated August 2011). Cochrane collaboration qualitative methods group, 2011. Available from URL http:// cqrmg.cochrane.org/supplemental-handbook-guidance.

21. Higgins JP, Altman DG, Gotzsche PC, Juni P, Moher D, Oxman $\mathrm{AD}$, et al. The Cochrane Collaboration's tool for assessing risk of bias in randomised trials. BMJ. 2011;343:d5928. https://doi.org/10. 1136/bmj.d5928.

22. Sterne JA, Hernan MA, Reeves BC, Savovic J, Berkman ND, Viswanathan M, et al. ROBINS-I: a tool for assessing risk of bias in non-randomised studies of interventions. BMJ. 2016;355:i4919. https://doi.org/10.1136/bmj.i4919.

23. Berry DL, Halpenny B, Hong F, Wolpin S, Lober WB, Russell KJ, et al. The personal patient profile-prostate decision support for men with localized prostate cancer: a multi-center randomized trial. Urol Oncol. 2013;31(7):1012-21. https://doi.org/10.1016/j.urolonc. 2011.10.004.

24. Bosco JL, Halpenny B, Berry DL. Personal preferences and discordant prostate cancer treatment choice in an intervention trial of men newly diagnosed with localized prostate cancer. Health Qual Life Outcomes. 2012;10:123. https://doi.org/10.1186/1477-7525-10123.

25. Auvinen A, Hakama M, Ala-Opas M, Vornanen T, Leppilahti M, Salminen $\mathrm{P}$ et al. A randomized trial of choice of treatment in prostate cancer: the effect of intervention on the treatment chosen. BJU Int. 2004;93(1):52-6; discussion 6. https://doi.org/10.1111/j. 1464-410x.2004.04554.x.

26. Feldman-Stewart D, Brundage MD, Siemens R, Skarsgard D. A randomized controlled trial comparing two educational booklets on prostate cancer. Can J Urol. 2006;13(6):3321-6.

27. Hack TF, Pickles T, Bultz BD, Ruether JD, Degner LF. Impact of providing audiotapes of primary treatment consultations to men with prostate cancer: a multi-site, randomized, controlled trial. Psychooncology. 2007;16(6):543-52. https://doi.org/10.1002/pon. 1094.

28. Diefenbach MA, Mohamed NE, Butz BP, Bar-Chama N, Stock R, Cesaretti $J$ et al. Acceptability and preliminary feasibility of an internet/CD-ROM-based education and decision program for early-stage prostate cancer patients: randomized pilot study. J Med Internet Res. 2012;14(1):e6. https://doi.org/10.2196/jmir. 1891.

29. Feldman-Stewart D, Tong C, Siemens R, Alibhai S, Pickles T, Robinson $\mathrm{J}$ et al. The impact of explicit values clarification exercises in a patient decision aid emerges after the decision is actually made: evidence from a randomized controlled trial. Med Decis Making. 2012;32(4):616-26. https://doi.org/10.1177/ 0272989X11434601.

30. Hacking B, Wallace L, Scott S, Kosmala-Anderson J, Belkora J, McNeill A. Testing the feasibility, acceptability and effectiveness of a 'decision navigation' intervention for early stage prostate cancer patients in Scotland-a randomised controlled trial. Psychooncology. 2013;22(5):1017-24. https://doi.org/10.1002/ pon.3093.

31. Chabrera C, Zabalegui A, Bonet M, Caro M, Areal J, Gonzalez JR, et al. A decision aid to support informed choices for patients recently diagnosed with prostate cancer: a randomized controlled trial. Cancer Nurs. 2015;38(3):E42-50. https://doi.org/10.1097/NCC. 0000000000000170 .

32. Song L, Tyler C, Clayton MF, Rodgiriguez-Rassi E, Hill L, Bai J et al. Patient and family communication during consultation visits: the effects of a decision aid for treatment decision-making for localized prostate cancer. Patient Education \& Counseling. 2017;100(2):267-75. https://doi.org/10.1016/j.pec.2016.09.012.

33. Cuypers M, Lamers RED, Kil PJM, van de Poll-Franse LV, de Vries M. Impact of a web-based prostate cancer treatment decision aid on patient-reported decision process parameters: results from the prostate cancer patient centered care trial. Support Care Cancer. 2018;26(11):3739-48. https://doi.org/10.1007/s00520018-4236-8.

34. Onel E, Hamond C, Wasson JH, Berlin BB, Ely MG, Laudone VP et al. Assessment of the feasibility and impact of shared decision making in prostate cancer. Urology. 1998;51(1):63-6. https://doi. org/10.1016/s0090-4295(97)00494-9.

35. Kim SP, Knight SJ, Tomori C, Colella KM, Schoor RA, Shih L, et al. Health literacy and shared decision making for prostate cancer patients with low socioeconomic status. Cancer Investig. 2001;19(7):684-91. https://doi.org/10.1081/cnv-100106143.

36. McGregor S. Information on video format can help patients with localised prostate cancer to be partners in decision making. Patient Education \& Counseling. 2003;49(3):279-83. https://doi.org/10. 1016/s0738-3991(02)00187-8

37. Feldman-Stewart D, Brundage MD, Van Manen L, Svenson O. Patient-focussed decision-making in early-stage prostate cancer: insights from a cognitively based decision aid. Health Expect. 2004;7(2):126-41. https://doi.org/10.1111/j.1369-7625.2004. 00271.xHEX271.

38. Holmes-Rovner M, Stableford S, Fagerlin A, Wei JT, Dunn RL, Ohene-Frempong J et al. Evidence-based patient choice: a prostate cancer decision aid in plain language. BMC Med Inform Decis Mak. 2005;5:16. https://doi.org/10.1186/1472-6947-5-16. 
39. Isebaert S, Van Audenhove C, Haustermans K, Junius S, Joniau S, De Ridder $\mathrm{K}$ et al. Evaluating a decision aid for patients with localized prostate cancer in clinical practice. Urol Int. 2008;81(4):383-8. https://doi.org/10.1159/000167833.

40. Anderson C, Carter J, Nattress K, Beale P, Philp S, Harrison J, et al. "The booklet helped me not to panic": a pilot of a decision aid for asymptomatic women with ovarian cancer and with rising CA-125 levels. Int J Gynecol Cancer. 2011;21(4):737-43. https://doi.org/ 10.1111/IGC.0b013e3181 fe8b57.

41. Formica MK, Wason S, Seigne JD, Stewart TM. Impact of a decision aid on newly diagnosed prostate cancer patients' understanding of the rationale for active surveillance. Patient Education \& Counseling. 2017;100(5):812-7. https://doi.org/10.1016/j.pec. 2016.11.019.

42. Lamers RE, Cuypers M, de Vries M, van de Poll-Franse LV, Ruud Bosch JL, Kil PJ. How do patients choose between active surveillance, radical prostatectomy, and radiotherapy? The effect of a preference-sensitive decision aid on treatment decision making for localized prostate cancer. Urol Oncol. 2017;35(2):37 e9- e17. https://doi.org/10.1016/j.urolonc.2016.09.007.

43. Myers RE, Leader AE, Censits JH, Trabulsi EJ, Keith SW, Petrich $\mathrm{AM}$, et al. Decision support and shared decision making about active surveillance versus active treatment among men diagnosed with low-risk prostate cancer: a pilot study. J Cancer Educ. 2018;33(1):180-5. https://doi.org/10.1007/s13187-016-1073-7.

44. Brito JP, Moon JH, Zeuren R, Kong SH, Kim YG, Iniguez-Ariza NM, et al. Thyroid cancer treatment choice: a pilot study of a tool to facilitate conversations with patients with papillary microcarcinomas considering treatment options. Thyroid. 2018;28(10):1325-31. https://doi.org/10.1089/thy.2018.0105.

45. Jayadevappa R, Chhatre S, Gallo JJ, Wittink M, Morales KH, Lee DI, et al. Patient-centered preference assessment to improve satisfaction with care among patients with localized prostate Cancer: a randomized controlled trial. J Clin Oncol. 2019;37(12): 964-73. https://doi.org/10.1200/JCO.18.01091.

46. Goldwag J, Marsicovetere P, Scalia P, Johnson HA, Durand MA, Elwyn $\mathrm{G}$ et al. The impact of decision aids in patients with colorectal cancer: a systematic review. BMJ Open. 2019;9(9):e028379. https://doi.org/10.1136/bmjopen-2018-028379.

47. Leighl NB, Shepherd HL, Butow PN, Clarke SJ, McJannett M, Beale PJ et al. Supporting treatment decision making in advanced cancer: a randomized trial of a decision aid for patients with advanced colorectal cancer considering chemotherapy. J Clin Oncol. 2011;29(15):2077-84. https://doi.org/10.1200/JCO.2010.32.0754.

48. Miles A, Chronakis I, Fox J, Mayer A. Use of a computerised decision aid (DA) to inform the decision process on adjuvant chemotherapy in patients with stage II colorectal cancer: development and preliminary evaluation. BMJ Open. 2017;7(3):e012935. https:// doi.org/10.1136/bmjopen-2016-012935.

49. Wu RC, Boushey RP, Scheer AS, Potter B, Moloo H, Auer R, et al. Evaluation of the rectal cancer patient decision aid: a before and after study. Dis Colon Rectum. 2016;59(3):165-72. https://doi.org/ 10.1097/DCR.000000000000052800003453-201603000-00002.

50. Drug, Therapeutics B. An introduction to patient decision aids. BMJ. 2013;347:f4147. https://doi.org/10.1136/bmj.f4147.

51. Penson DF. Factors influencing patients' acceptance and adherence to active surveillance. J Natl Cancer Inst Monogr. 2012;2012(45): 207-12.

Publisher's Note Springer Nature remains neutral with regard to jurisdictional claims in published maps and institutional affiliations. 